\title{
Analysis of Enterprise Human Resource Management and the Firm Performance
}

\author{
Yuan Qian ${ }^{1, \text { a }}$, Lei Zhou ${ }^{1, b}$, Xiuping Liu ${ }^{1, c}$ \\ ${ }^{1}$ Nanchang Institute of Science \& Technology, Nanchang, Jiangxi, 330000 \\ ${ }^{a}$ email, ${ }^{b}$ email, ${ }^{c}$ email
}

Keywords: Enterprise Management, Human Resource, Film Performance

\begin{abstract}
With the development of the market economy and the intensification of competition, the enterprise performance has become the main aspect of the enterprise to obtain the competitive advantage. Enterprises can only consider a wide range of factors in order to improve their own performance, but can not ignore the main factors of human resources. However, the early human resources management and enterprise development requirements do not match, so gradually formed a strategic human resources management, human resources management gradually rose to the strategic level.
\end{abstract}

\section{Introduction}

Since the 21st century, the rapid development of global information technology, knowledge economy in the market in a dominant position, between various industries and enterprises across the competition began to intensify, companies began to pay attention to the core competitiveness of the increase. And human resources is an important resource for enterprises to improve their core competitiveness. Therefore, the study of strategic human resource management was born, and become the main problem of many scholars. In 1980, the birth of strategic human resource management, it is mainly a corporate strategy and human resources closely integrated with human resources management activities. The idea of this theory is that human resources can win competitive advantage for enterprises, and pay more attention to human resources and business strategy to match the degree. With the rapid development of market economy, many enterprises began to develop according to market changes for their own development strategy, strategic human resources management began to dominate the enterprise management elements. In the work of strategic human resource management, human resources is an important resource of enterprises, and human resources and enterprise strategy to adapt to the strategic human resources management is the core idea. Strategic human resources management has been more than 20 years of development history, many scholars at home and abroad are constantly on its research, especially the current human resources is the business in the competition to occupy a favorable position in the main resource. With the strategic human resources management in the enterprise gradually occupy the core position, many problems surfaced, these problems need to be resolved. For example, what is the relationship between strategic human resource management and firm performance; if strategic human resource management can have an effect on firm performance, what is the mechanism of action between them and how the results are; Background or environmental conditions; how can human resource policies be used to improve the performance of firms; these questions require strategic human resource management researchers to answer. The answers to these questions will clarify the relationship between strategic human resource management and corporate performance, thus laying the foundation for strategic human resource management. Therefore, scholars pay special attention to this aspect of the study.

\section{The Mechanism of Human Resource Management to Enterprise Performance}

Enterprise implementation of strategic human resources management policy, the ultimate goal is to promote business performance can be improved. Human capital theory, role behavior theory and resource-based theory researchers believe that strategic human resource management can have a 
role in business performance. This role is mainly reflected in the financial performance, the implementation of corporate strategy, to achieve the strategic objectives of several aspects. This chapter is based on the analysis of the existing literature on the basis of the strategic human resources management to explore the role of corporate performance mechanism.

Human resource costs mainly cover the costs of obtaining, applying and maintaining human resources. Human resources can influence business performance. If the cost of human resources increases, then the total cost of consumption will increase, then the company's operating performance will decline, on the contrary, if the enterprise consumption of human resources costs are relatively low, then the enterprise's income will be high. Human resources costs are: first, access to costs. Mainly refers to the enterprise for the recruitment of employees for the development of the cost of staff and because of the recruitment and abandon the opportunity cost; second, the use of cost. Mainly refers to the staff and the enterprise to find a new enterprise for the development of the requirements of the staff and pay some direct and indirect costs.

Customer-oriented, internal collaboration and competition-oriented three aspects of the enterprise's market-oriented, these three aspects are dialectical unity, mutual coordination and promotion. The advent of the market economy, exacerbated the competition between enterprises, companies began to win competitive advantage and efforts, and these advantages need to get through the strategy to complete, only in this way enterprises can occupy a favorable position for their own profit. And market-oriented to enable enterprises to quickly understand the changes in customer needs, so as to respond to the development of the market, to identify the road for enterprise innovation, and ultimately to promote the business process has begun to change. At the same time, the market environment changes, companies can quickly control the target market, and then set up barriers to entry for other enterprises to bring obstacles, so as to promote their own profitability. In short, market-oriented can influence customer loyalty, business innovation, business important business processes and finance.

The learning power of the enterprise mainly includes the attitude of the staff, the ability to learn and the time spent on learning. Informatization makes the knowledge economy more and more important in the market, if the enterprise has faster and better learning than the competition, then the enterprise will be able to win in the competition. There are two aspects of the company's ability to have strong learning, specifically: on the one hand, companies can rely on some resources to develop suitable for enterprise development knowledge and skills; the other hand, to enable employees to share the knowledge applied to work Positions, and thus the enterprise innovation and reform, increase the competitive advantage of enterprises, enhance business performance. While the enterprise's learning ability to a certain extent, will also affect the internal business process. Through long-term learning, and the knowledge and skills learned to use the specific business process optimization, this can shorten the production cycle of the product, improve the efficiency of business processes, not only can reduce production costs, but also timely response Market changes, improve the competitiveness of enterprises. In addition, high-intensity learning can enable enterprises to obtain high core competitiveness, it can promote the profitability of enterprises to improve, so that the customer's needs are met. First, the strong enterprise learning ability to the theoretical knowledge and technology quickly applied to the production of enterprises, thereby improving the quality of products and services to enhance customer loyalty to the enterprise; second, to promote more customers To participate in the purchase of products to improve the image of consumers in the minds of consumers, and third, the enterprise's learning ability to force the enterprise learning atmosphere changes, it can promote enterprise innovation. Enterprise employees are through continuous learning, to change the concept, brainstorming and continuous innovation in the work, so as to promote the development of enterprises.

\section{Optimizing the Effect of Human Resource Management on Enterprise Performance}

The market environment is constantly changing, prompting enterprises to pay more attention to the role of strategy for enterprise development, but also to make enterprises to develop and implement the strategy has become Yu complex. Enterprises in order to use limited resources to get enough 
market share, we must do a good job of human resources management, so the strategic human resources management status gradually improved. Therefore, the implementation of human resources management policies must be closely around the enterprise's strategy and can not just rely on the strategy of enterprises to provide different services, in the absence of existing human resources analysis of the status quo under the premise of the staff blind Of the business strategy around the work, so that contrary to the strategic objectives of the enterprise. In order to make the strategic objectives of the enterprise faster to achieve, we must apply the human resources work to the enterprise strategy, while the existing human resources to be analyzed on the basis of the development of enterprise development strategy, based on the development of human Resource management strategies to improve their competitive advantage in the position. Moreover, the strategic human resources management strategy must be carried out at the same time, so that the market environment changes in the premise of making timely adjustments, the only way to make the core competitiveness of enterprises to be improved.

Under the principle of fairness and fairness, establish a perfect salary system and performance evaluation system to make full use of human resources as the main objective, so as to develop a welfare strategy suited to the development of the enterprise, so that the staff is devoted to the work, so as to The smallest human resource consumption to operate, to promote a variety of obstacles to the development of staff to eliminate the factors. While the staff of the wage level, to stimulate the purpose of each employee, so as to encourage employees to work for the enterprise, try to play their talents. Such as the staff of the job responsibilities and contribution rate and the work of the enterprise linked to the development of enterprises to contribute to the career of employees to enhance their career and enhance their enthusiasm for the work. If the employees have a good behavior, then the performance of enterprises can be improved. Therefore, we must monitor the behavior of employees, employees can be bound to act, to promote the healthy development of enterprises, promote business performance. Supervise the staff in strict accordance with the qualifications to act, and the qualifications as their work guidelines, so as to improve their own work efficiency, restraint their own behavior. With key performance indicators to guide the behavior of employees, so that employees pay high, the promotion of the job to provide a basis for reference, to promote the standardization of staff engaged in the work. Enterprise development needs to improve their ability to respond to the impact of changes in the external environment, which requires the establishment of a more comprehensive competition out of the mechanism, the enterprise development of useless employees to clear the enterprise, at the same time, need to bring some challenges to employees, Enthusiasm to enhance, threw himself into the work, improve their own work efficiency. The main business is taken through the external competition to go to work and through internal competition out of the enterprise useless personnel two ways of competition out of the mechanism.

In the era of knowledge economy, enterprises in a complex external environment, enterprises in order to gain a place in the competition, we must be able to deal with the impact of various forces. This requires enterprises to look at the world from a strategic perspective, not only to consider the impact of the internal environment of enterprises, but also consider the impact of external environment on the enterprise, to build a human resources management system to promote the competitiveness of enterprises to improve. According to the current and future development needs of enterprises, in order to improve the staff's knowledge and skills, we need to adapt to the external staff, recognized enterprises and enhance business loyalty and other aspects of training.

Knowledge economy in the market is to occupy a dominant position, which requires enterprises to tap more human resources as their development support. Enterprises in order to achieve long-term stability of the development must pay attention to human resources management. And the establishment of a sound human resources management system for enterprise development has been irresistible, with information technology management staff knowledge and skills, easy to understand the staff and the requirements of the requirements of the job, forcing enterprises to obtain talent, improve staff work efficiency, in order to achieve business performance improvement. 


\section{Conclusion}

Based on the analysis of a large number of literatures and the in-depth investigation of the enterprises, strategic human resource management is positively related to the performance of enterprises, and strategic human resource management can rely on some intermediate variables to influence enterprise performance, such as strategic human resource management Impact on employee behavior and attitudes that affect business performance. And found that strategic human resource management in the promotion of corporate performance, such as the development strategy, such as departure from the effective strategic human resources management mechanism is lacking, training does not focus on long-term goals, corporate culture is not put into practice and workers The quality of the existence of great differences and do not attach importance to corporate culture and other issues.

\section{References}

[1] Lu Jie, Yu Ying. Online channel construction and traditional enterprise performance empirical research [J]. Shanghai Management Science, 2013 (02)

[2] Zeng Shengjun. The relationship between learning orientation and corporate performance: the intermediary role of innovation ability [J]. Productivity Research, 2011 (01)

[J] .Journal of Jimei University, 2008 (02). [J] .Journal of Jimei University, 2008 (02)

[4] Qin Xiaolei, Yang Dongtao, Wei Jiangru. Empirical Study on the Relationship between Innovation Strategy, Employee Training and Firm Performance [J]. Chinese Journal of Management, 2007 (03)

[5] Zhu Julan, Yang Zhili. Research on the Relationship between Social Capital and Firm Performance: An Empirical Study of Zhejiang [J]. Economist, 2013 (02)

[6] Sun Weifeng. The Impact of Scale on the Relationship between Innovation and Firm Performance - An Empirical Study from Chinese Listed Companies [J] .Bujing Ji, 2013 (02) 